\title{
microRNA-564 inhibits the aggressive phenotypes of papillary thyroid cancer by directly targeting astrocyte-elevated gene-I
}

This article was published in the following Dove Press journal: OncoTargets and Therapy

\author{
Zhenzhen Song' \\ Huimei Yang' \\ Xia $\mathrm{Wu}^{2}$ \\ Cui Kong ${ }^{2}$ \\ Cong'e $\mathrm{Xu}^{3}$ \\ 'Department of Laboratory, The Third \\ People's Hospital of Linyi, Linyi, Shandong \\ 276023, People's Republic of China; \\ ${ }^{2}$ Department of Oncology, The Third \\ People's Hospital of Linyi, Linyi, Shandong \\ 276023, People's Republic of China; \\ ${ }^{3}$ Department of Radiation Oncology, \\ Linyi Cancer Hospital, Linyi, Shandong \\ 276000, People's Republic of China
}

Background: Accumulating evidence has revealed that an increasing number of microRNAs (miRNAs) are dysregulated in papillary thyroid cancer (PTC) and that their dysregulation plays an important role in PTC onset and progression. Reportedly, miRNA-564 (miR-564) is downregulated in several types of human cancer. However, its expression profile and specific functions in PTC remain unclear to date.

Methods: In this study, we used reverse transcription-quantitative polymerase chain reaction to detect miR-564 expression in PTC tissues and cell lines. Further, the regulatory roles of miR-564 in the malignant development of PTC in vitro and in vivo were examined using a series of functional experiments. In addition, the possible underlying mechanisms and signaling pathways involved were investigated.

Results: We demonstrated that miR-564 expression markedly decreased in PTC tissues and cell lines, and this decrease correlated with the lymph node metastasis and tumor-nodemetastasis stage. miR-564 upregulation significantly inhibited cell proliferation, migration, and invasion and induced cell apoptosis in vitro as well as hindered tumor growth in vivo. Furthermore, astrocyte-elevated gene-1 (AEG-1) was identified as a direct target gene of miR-564 in PTC cells. Its expression was upregulated and inversely correlated with miR-564 expression in clinically PTC tissues. Additionally, the silencing of AEG-1 expression could imitate the action of miR-564 overexpression in PTC cells. Remarkably, the restoration of AEG-1 expression partially abolished the tumor-suppressing effects induced by a miR-564 upregulation in PTC cells. Ectopic miR-564 expression deactivated the PTEN/Akt pathway in PTC cells in vitro and in vivo.

Conclusion: Overall, the findings of the current study suggest that miR-564 is a tumorsuppressive miRNA that exerts crucial roles in the development and progression of PTC. Therefore, this miRNA might be a promising candidate target in the anticancer treatment of patients with PTC.

Keywords: microRNA-564, papillary thyroid cancer, astrocyte elevated gene-1, aggressive phenotypes

\section{Introduction}

Thyroid cancer, originating from follicular or parafollicular thyroid cells, is the most common endocrine malignancy. ${ }^{1}$ Globally, approximately 300,000 novel thyroid cancer cases and 40,000 mortalities caused by thyroid cancer occur annually. ${ }^{2}$ Thyroid cancer can primarily be divided into four subtypes: papillary thyroid cancer (PTC), follicular thyroid cancer, medullary thyroid cancer, and anaplastic thyroid cancer. ${ }^{3}$ Among these, PTC is the most common subtype of
Correspondence: Cong'e Xu

Department of Radiation Oncology, Linyi Cancer Hospital, No. 6, Lingyuan East

Street, Linyi, Shandong 276000, People's

Republic of China

Email xuconge@yeah.net 
thyroid cancer, accounting for more than $80 \%$ of all thyroid cancer cases. ${ }^{4}$ Genetic and epigenetic alterations have been shown to play a crucial role in the genesis and development of PTC; however, the detailed molecular mechanisms underlying these changes remain poorly characterized. 5 The primary therapeutic strategies currently employed against PTC, including surgical resection, radioiodine therapy, and adjuvant long-term thyrotropin suppression therapy, result in an excellent prognosis in the vast majority of patients; however, recurrence and metastasis are frequently associated with poor clinical outcomes. $^{7,8}$ Therefore, the mechanisms involved in the pathogenesis of PTC need to be clarified to aid in the development of improved therapeutic approaches for patients with PTC.

microRNAs (miRNAs) are a group of endogenous, singlestranded, and non-coding 18-24 nucleotide-long RNA molecules. ${ }^{9}$ So far, more than 1,400 miRNAs have been identified in the human genome. ${ }^{10}$ miRNAs are capable of regulating gene expression at the transcriptional or posttranscriptional level by partially base pairing with the $3^{\prime}$ untranslated regions ( $3^{\prime}$-UTRs) of their target genes, triggering mRNA degradation, and/or transcriptional silencing. ${ }^{11}$ Aberrations in miRNA expression have been reported in nearly all types of human cancer, suggesting that miRNAs participate in carcinogenesis and cancer progression. ${ }^{12-14}$ Promising studies have discovered that various miRNAs are dysregulated in PTC and exert tumor-suppressive or oncogenic roles. ${ }^{15-17}$ miRNA dysregulation is implicated in various biological processes and plays a crucial role in the oncogenicity of PTC. ${ }^{18,19}$ Therefore, further investigation into the specific roles played by miRNAs in PTC may facilitate the identification of effective targets for the treatment of patients with this disease.

miR-564 is reportedly downregulated in several types of human cancer and involved in carcinogenesis and cancer progression. ${ }^{20-25}$ However, its expression profile and specific functions in PTC remain unclear as yet. Accordingly, the purpose of the current study was to determine miR-564 expression in PTC and assess its clinical significance. In addition, the expression profile of AEG-1 in PTC tissues was also determined. The effects of miR-564 on the aggressive behavior in PTC were investigated using a series of in vitro and in vivo experiments. Furthermore, the possible underlying mechanisms and signaling pathways involved were investigated. This study provides novel insights into the crucial role of the miR-564/AEG-1/PTEN/Akt pathway in the development and progression of PTC.

\section{Materials and methods}

\section{Ethical statement}

The experimental protocols of this study were approved by the Ethics Committee of The Third People's Hospital of Linyi (170011). This study was conducted in accordance with the principles of the Declaration of Helsinki, and written informed consent was provided by all patients enrolled in the study.

\section{Tissue samples and cell lines}

Paired PTC and normal adjacent tissue samples were obtained from 47 patients who underwent surgical resection at The Third People's Hospital of Linyi. None of these patients received any preoperative therapy, including radioiodine therapy, or chemotherapy. Following collection, all tissues were rapidly frozen in liquid nitrogen and then stored at $-80^{\circ} \mathrm{C}$ for later use.

In total, three human PTC cell lines (TPC-1, BCPAP, and HTH83) and a normal human thyroid cell line (HT-ori 3) were bought from the American Type Culture Collection (Manassas, VA, USA). All cell lines were cultured in Dulbecco's modified Eagle's medium (DMEM; Gibco; Thermo Fisher Scientific, Inc., Waltham, MA, USA) containing $10 \%$ heat-inactivated fetal bovine serum (FBS; Hyclone, Logan, UT, USA) and 1\% antibiotic/antimycotic solution (Sigma-Aldrich; Merck KGaA, Darmstadt, Germany). All cell lines were maintained at $37^{\circ} \mathrm{C}$ in a humidified incubator supplied with $5 \% \mathrm{CO}_{2}$.

\section{Cell transfection}

miR-564 mimics and negative control miRNA mimics (miR-NC) were constructed by Shanghai GenePharma Co., Ltd. (Shanghai, China). Astrocyte-elevated gene-1 (AEG-1), small interfering RNA (siRNA), and scrambled negative control siRNA were obtained from Guangzhou RiboBio Biotechnology Co., Ltd. (Guangzhou, China). The full length of AEG-1 lacking 3'-UTR was amplified by Shanghai GenePharma Co., Ltd., and inserted into a plasmid, pcDNA3.1, referred to as pc-AEG-1. Cells were inoculated into six-well plates at a density of $6 \times 10^{5}$ cells/well $24 \mathrm{hrs}$ prior to transfection. Transient transfection was performed using Lipofectamine ${ }^{\circledR} 2000$ reagent (Invitrogen; Thermo Fisher Scientific, Inc.), according to the manufacturer's instructions. Then, the transfected cells were harvested following different incubation times and used for subsequent functional assays. 


\section{Isolation of total RNA and reverse transcription-quantitative polymerase chain reaction ( $R T-q P C R$ )}

Total RNA was extracted from tissue specimens and cultured cells using TRIzol ${ }^{\circledR}$ (Thermo Fisher Scientific, Inc.). Total RNA was reverse transcribed into complementary DNA (cDNA) using a miScript Reverse Transcription kit (Qiagen GmbH, Hilden, Germany). To quantify the miR564 expression levels, RT-qPCR was conducted using a miScript SYBR Green PCR kit (Qiagen GmbH, Hilden, Germany). U6 small nuclear RNA was used as an endogenous control for miR-564. For the quantification of AEG-1, first-strand cDNA was prepared from total RNA using a RevertAid ${ }^{\mathrm{TM}}$ First-Strand cDNA Synthesis kit (Thermo Fisher Scientific, Inc.), followed by qPCR with an SYBR Green PCR Master mix (TaKaRa, Dalian, China). AEG-1 expression was normalized to glyceraldehyde-3-phosphate dehydrogenase (GAPDH). Further, relative gene expression was calculated using the $2^{-\Delta \Delta \mathrm{Cq}}$ method. ${ }^{26}$

\section{3-(4,5-dimethyl-2-thiazolyl)-2,5-diphenyl- 2-H-tetrazolium bromide (MTT) assay}

MTT assay was performed to determine cell proliferation, in accordance with the manufacturer's instructions. In brief, transfected cells were harvested following 24-hr incubation and resuspended in DMEM supplemented with $10 \%$ FBS. A total of $200 \mu \mathrm{L}$ culture medium containing $3 \times 10^{3}$ cells was placed in each well of a 96-well plate. Cell proliferation was determined at four time points: 0 , 24, 48, and $72 \mathrm{hrs}$ following incubation. Following the addition of $20 \mu \mathrm{L}$ MTT solution $(5 \mathrm{mg} / \mathrm{mL}$; SigmaAldrich) to each well, the samples were incubated at $37^{\circ}$ $\mathrm{C}$ with $5 \% \mathrm{CO}_{2}$ for an additional $4 \mathrm{hrs}$. Next, the culture medium was carefully removed, and formazan crystals formed were dissolved in dimethyl sulfoxide. Optical density (OD) at a wavelength of $490 \mathrm{~nm}$ was measured using an ELISA microplate reader (Bio-Rad Laboratories, Inc., Hercules, CA, USA).

\section{Cell apoptosis assay}

To analyze apoptosis, transfected cells were collected at $48 \mathrm{hrs}$ following transfection with trypsin (Gibco; Thermo Fisher Scientific, Inc.) and washed thrice with an ice-cold phosphate buffer solution (Gibco; Thermo Fisher Scientific, Inc.) at $4^{\circ} \mathrm{C}$. The apoptosis rate was estimated using an Annexin V-fluorescein isothiocyanate apoptosis detection kit (Biolegend, San Diego, CA, USA). Briefly, the cells were resuspended in $100 \mu \mathrm{L}$ of $1 \times$ binding buffer and then stained with $5 \mu \mathrm{L}$ Annexin $\mathrm{V}-$ fluorescein isothiocyanate and $5 \mu \mathrm{L}$ propidium iodide. Following 20-min culturing at room temperature in the absence of light, apoptotic cells were measured by flow cytometry (FACScan ${ }^{\mathrm{TM}}$, BD Biosciences, Franklin Lakes, NJ, USA).

\section{Transwell assay}

Transwell chambers $(8-\mu \mathrm{m}$ pores; BD Biosciences, San Jose, CA, USA) were used for migration analysis. Briefly, $5 \times 10^{4}$ transfected cells were suspended in 200 $\mu \mathrm{L}$ FBS-free DMEM medium and seeded into the top compartment of a transwell chamber. Lower compartments were filled with $600 \mu \mathrm{L}$ DMEM medium supplemented with $10 \%$ FBS. Following 24-hr incubation at $37^{\circ} \mathrm{C}$, the non-traversed cells retained in the underside of the top chamber were gently wiped away. Next, migrated cells were fixed in $100 \%$ methanol and stained with $0.1 \%$ crystal violet. Invasion analyses were performed using the same procedure as for migration assay, except that the chambers were precoated with Matrigel (BD Biosciences). The number of migrated and invaded cells was counted in five randomly selected fields per chamber using a light microscope (Olympus, Tokyo, Japan).

\section{In vivo tumor xenograft model}

The cells transfected with miR-564 mimics or miR-NC were harvested following 24-hr incubation and subcutaneously injected into the flanks of BALB/c nude mice (Shanghai SLAC Laboratory Animal Co. Ltd., Shanghai, China). A total of eight nude mice were obtained and divided into two groups ( $\mathrm{n}=4$ for each group): miR-564 mimics and miR-NC groups: The size of the tumor xenograft in all nude mice was recorded every 4 days using a caliper, and tumor volumes were calculated using this equation: volume $=\left(\right.$ length $\left.\times(\text { width })^{2}\right) / 2$. All nude mice were sacrificed 4 weeks following inoculation and formed tumor xenografts were resected. Tumor xenografts were weighed and reserved as appropriate for RT-qPCR and Western blot analysis. All experimental procedures were approved by the Ethics Committee of The Third People's Hospital of Linyi, and were carried out according to the guidance of Animal Protection Law of the People's Republic of China-2009 for experimental animals. 


\section{Bioinformatics analysis and luciferase reporter assay}

Targetscan (www.targetscan.org/vert_71) and MiRanda (http://www.microrna.org) were used to search the putative target genes of miR-564.

Wild-type (wt) 3'-UTR of AEG-1 containing predicted miR-564 binding sites was amplified by Shanghai GenePharma Co., Ltd., and inserted into the psiCHECK2 luciferase expression vector (Promega Corporation, Madison, WI, USA) to generate psiCHECK-wt-AEG-1-3'UTR. Similarly, mutant (mut) AEG-1 3'-UTR was cloned into the psiCHECK-2 luciferase expression vector to generate psiCHECK-mut-AEG-1-3'-UTR. The chemically synthesized reporter vectors were co-transfected with miR-564 or miR-NC into the cells using Lipofectamine ${ }^{\circledR}$ 2000 reagent. After 24 hrs, transfected cells were collected and prepared to measure their firefly and Renilla luciferase activities using a Dual-Luciferase Reporter Assay System (Promega). Renilla luciferase activity was normalized to that of firefly luciferase.

\section{Western blot analysis}

Radioimmunoprecipitation assay lysis buffer (SigmaAldrich; Merck KGaA, Darmstadt, Germany) containing protease inhibitors (Roche Applied Science, Madison, WI, USA) was used to isolate total protein from cells or tissues. The quantification of total protein was performed using a bicinchoninic acid protein assay kit (Cwbiotech, Beijing, China). Equivalent quantities of total protein were separated by $10 \%$ SDS-PAGE and transferred to polyvinylidene difluoride membranes (Beyotime Institute of Biotechnology, Haimen, China). Then, the membranes were blocked for $2 \mathrm{hrs}$ at room temperature with non-fat powdered milk diluted in Tris-buffered saline containing $0.1 \%$ Tween 20 (TBST), followed by an overnight incubation with primary antibodies at $4{ }^{\circ} \mathrm{C}$. Next, the membranes were washed thrice with TBST prior to 2-hr incubation at room temperature with horseradish peroxidase-conjugated secondary antibody (ab6789 and ab6721; 1:5000 dilution; Abcam, Cambridge, MA, USA). The blots were observed using an Enhanced Chemiluminescence Detection System (Pierce; Thermo Fisher Scientific, Inc.). The following antibodies were used for Western blot analysis: mouse anti-human AEG-1 monoclonal primary antibody (sc517220; 1:1000 dilution; Santa Cruz Biotechnology, CA, USA), rabbit anti-human monoclonal PTEN (ab170941; 1:1000 dilution; Abcam), mouse anti-human monoclonal
p-Akt (sc-514032; 1:1000 dilution; Santa Cruz Biotechnology), mouse anti-human monoclonal Akt (sc81434; 1:1000 dilution; Santa Cruz Biotechnology), and mouse anti-human monoclonal GADPH antibody (ab125247; 1:1000 dilution; Abcam). GAPDH was used as a loading control.

\section{Statistical analysis}

Statistical Product and Service Solutions version 17.0 (IBM Corporation, Armonk, NY, USA) was employed to perform statistical analyses. All results are presented as means \pm standard deviation (SD). The correlation between miR-564 expression and clinicopathological parameters in patients with PTC was evaluated using chi-square test. Spearman's correlation analysis was used to assess the expression correlation between miR-564 and AEG-1 mRNA levels in PTC tissues. Further, Student's $t$-test and one-way analysis of variance with Bonferroni test were used to analyze differences between two and multiple groups, respectively. $P<0.05$ was considered statistically significant for all analyses.

\section{Results}

\section{miR-564 is downregulated in PTC tissues and cell lines}

To clarify the expression profile of miR-564 in PTC, we first examined miR-564 expression in 47 pairs of PTC tissues and normal adjacent tissues. The data obtained from RT-qPCR analysis indicated that the expression levels of miR-564 were lower in PTC tissues than in normal adjacent tissues (Figure 1A, $P<0.05)$. Next, we explored the association between miR-564 expression and clinicopathological parameters to reveal the clinical value of miR-564 in patients with PTC. Low miR-564 expression correlated with the lymph node metastasis $(P=0.002)$ and tumor-nodemetastasis (TNM) stage $(P=0.008)$ in patients with PTC (Table 1). However, the correlations between miR-564 and other clinicopathological characteristics were not significant (all $P>0.05$ ). Meanwhile, miR-564 expression was found to be significantly downregulated in all three tested PTC cell lines (TPC-1, BCPAP, and HTH83) compared with the expression in a normal human thyroid cell line (HT-ori3; Figure 1B, $P<0.05$ ). These results suggested that a reduction in miR-564 expression may be closely related to the development and progression of PTC. 

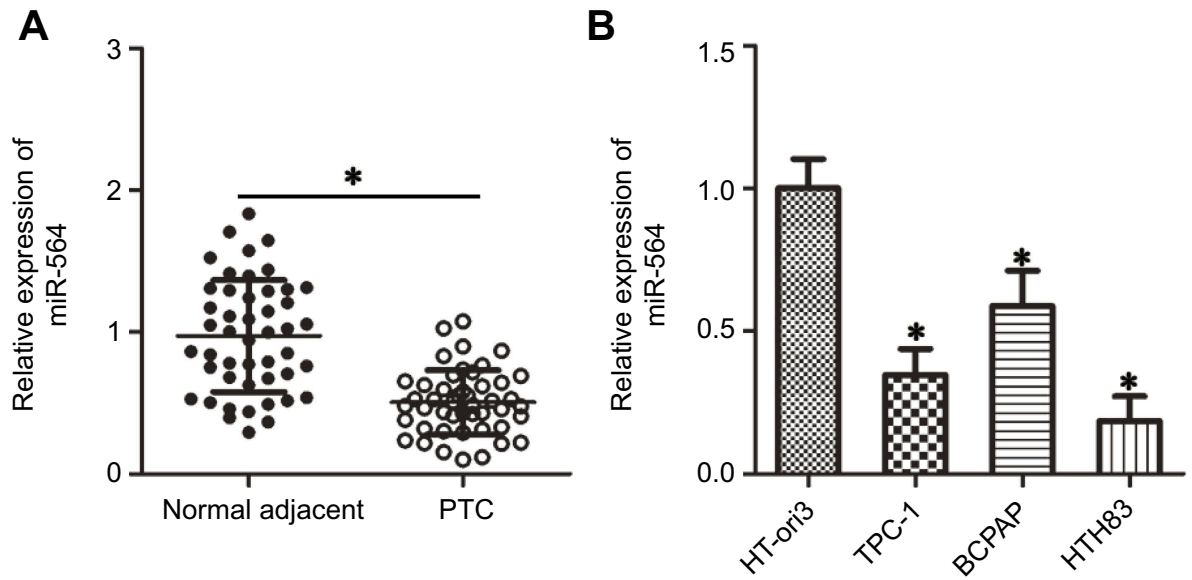

Figure I Expression of miR-564 is decreased in PTC tissues and cell lines. (A) Expression level of miR-564 in 47 pairs of PTC and normal adjacent tissues was detected using RT-qPCR. ${ }^{* P}<0.05$ compared with normal adjacent tissues. (B) RT-qPCR was used to determine miR-564 expression in a panel of PTC cell lines, including TPC-I, BCPAP, and HTH83. The normal human thyroid cell line HT-ori3 was used as a control. $* P<0.05$ compared with HT-ori3.

Table I Association of miR-564 expression and clinical characteristics of patients with PTC

\begin{tabular}{|l|l|l|l|}
\hline \multirow{2}{*}{ Characteristics } & \multicolumn{2}{|l|}{ miR-564 expression } & \multirow{2}{*}{$P$} \\
\cline { 2 - 3 } & Low & High & \\
\hline $\begin{array}{l}\text { Age (years) } \\
<60\end{array}$ & 17 & 15 & 0.760 \\
$\geq 60$ & 7 & 8 & \\
\hline $\begin{array}{l}\text { Gender } \\
\text { Male } \\
\text { Female }\end{array}$ & 10 & 7 & 0.512 \\
\hline $\begin{array}{l}\text { Tumor size (cm) } \\
<5\end{array}$ & 14 & 16 & \\
$\geq 5$ & 17 & 14 & 0.547 \\
\hline $\begin{array}{l}\text { Lymph node metastasis } \\
\text { Negative } \\
\text { Positive }\end{array}$ & 7 & 9 & \\
\hline $\begin{array}{l}\text { TNM stage } \\
\text { I-II } \\
\text { III-IV }\end{array}$ & 10 & 20 & $0.002^{*}$ \\
\hline
\end{tabular}

\section{miR-564 upregulation suppresses cell proliferation, migration, and invasion and induces cell apoptosis in PTC in vitro}

Among the three PTC cell lines, TPC-1 and HTH83 exhibited relatively lower miR-564 expression; therefore, these two cell lines were used in the subsequent functional experiments. To investigate the specific roles of miR-564, TPC-1 and HTH83 cells were transfected with miR-564 mimics or miR-NC. RTqPCR analysis demonstrated that miR-564 mimics significantly increased the endogenous expression of miR564 in TPC-1 and HTH83 cells compared with that in the miRNC group (Figure $2 \mathrm{~A}, P<0.05$ ). MTT assay was performed to investigate the effect of miR-564 overexpression on PTC cell proliferation. The results revealed that transfection with miR564 mimics significantly suppressed the proliferation of TPC-1 and HTH 83 cells (Figure 2B, $P<0.05$ ). Next, cell apoptosis assay was performed to determine the influence of miR-564 on apoptosis in PTC cells. Resumption of miR-564 expression significantly increased the percentage of apoptotic TPC-1 and HTH83 cells (Figure 2C, $P<0.05$ ). Furthermore, transwell assay showed that ectopic miR-564 expression significantly decreased the migratory (Figure 2D, $P<0.05$ ) and invasive (Figure 2E, $P<0.05$ ) capacities of TPC-1 and HTH83 cells. These results suggest that miR-564 plays an inhibitory role in the growth and metastasis of PTC cells in vitro.

\section{AEG-I is a direct target gene of miR-564 in PTC cells}

miRNA mainly functions through direct binding to the 3'UTR of its target gene, resulting in mRNA degradation and/ or transcriptional silencing. ${ }^{11}$ To explore the mechanisms associated with the tumor-suppressing roles of miR-564, bioinformatics analysis was conducted to predict the potential target of miR-564. The 3'-UTR region of AEG-1 was predicted to be a putative binding site for miR-564 because it harbored the regions matching the miR-564 seed sequences (Figure 3A). Accordingly, AEG-1 was selected for further validation because this gene has been implicated in the modulation of PTC occurrence and development. ${ }^{27-29}$ Luciferase reporter assay was employed to determine 


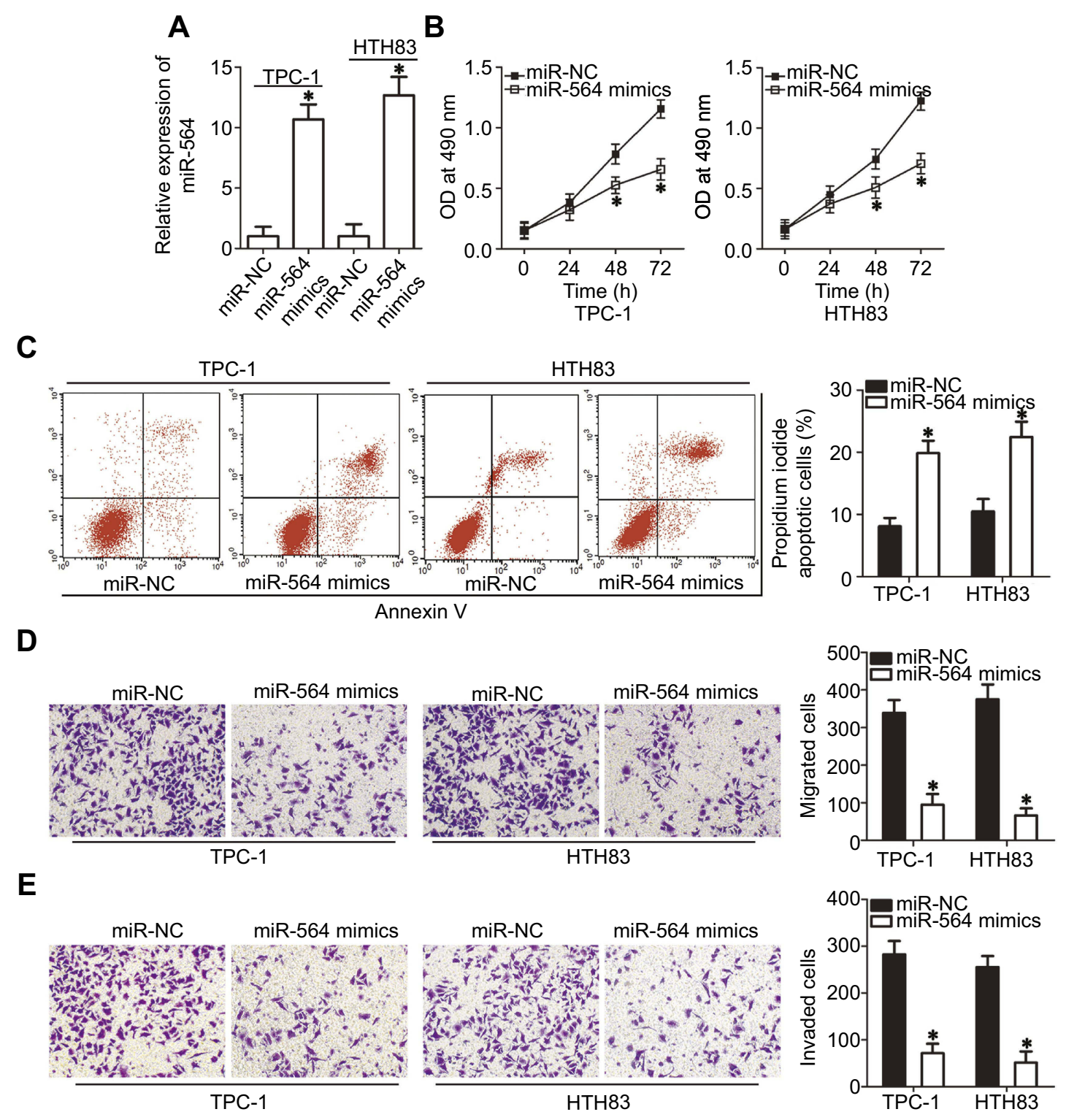

Figure 2 miR-564 reduces cell proliferation, migration, and invasion and induces apoptosis in PTC. (A) TPC-I and HTH83 cells were transfected with miR-564 mimics or miR-NC. The expression level of miR-564 was detected 48 hrs following transfection using RT-qPCR. $* P<0.05$ compared with miR-NC. (B) An MTT assay was used to analyze the proliferation of TPC-I and HTH83 cells following miR-564 mimic or miR-NC transfection. *P<0.05 compared with miR-NC. (C) TPC-I and HTH83 cells treated as abovementioned were collected following 48-hr culturing. The apoptosis rate was examined using a cell apoptosis assay. $* P<0.05$ compared with miR-NC. (D and $\mathbf{E})$ miR564 mimics or miR-NC were introduced into TPC-I and HTH83 cells. The capacity of migration and invasiveness was assessed using transwell assay. *P<0.05 compared with miR-NC.

whether the 3'-UTR of AEG-1 could be directly targeted by miR-564 in PTC cells. As shown in Figure 3B, enforced miR-564 expression significantly decreased luciferase activity in the wt 3'-UTR of AEG-1 in TPC-1 and HTH83 cells $(P<0.05)$; however, a mutation of the miR-564 binding site in the $3^{\prime}$-UTR of AEG-1 abrogated the luciferase response to miR-564. Furthermore, the effect of miR-564 on endogenous AEG-1 expression in PTC cells was investigated. TPC-1 and HTH83 cells transfected with mIR-564 mimics exhibited significantly decreased AEG-1 expression at the mRNA
(Figure 3C, $P<0.05$ ) and protein (Figure 3D, $P<0.05$ ) levels compared with that in the cells transfected with miR-NC. These results suggest that AEG-1 is a novel target of miR564 in PTC cells.

\section{miR-564 is negatively correlated with AEG-I in PC tissues}

Next, we investigated AEG-1 expression in PTC tissues and explored the expression relationship between miR-564 and AEG-1. RT-qPCR revealed that the expression level of 

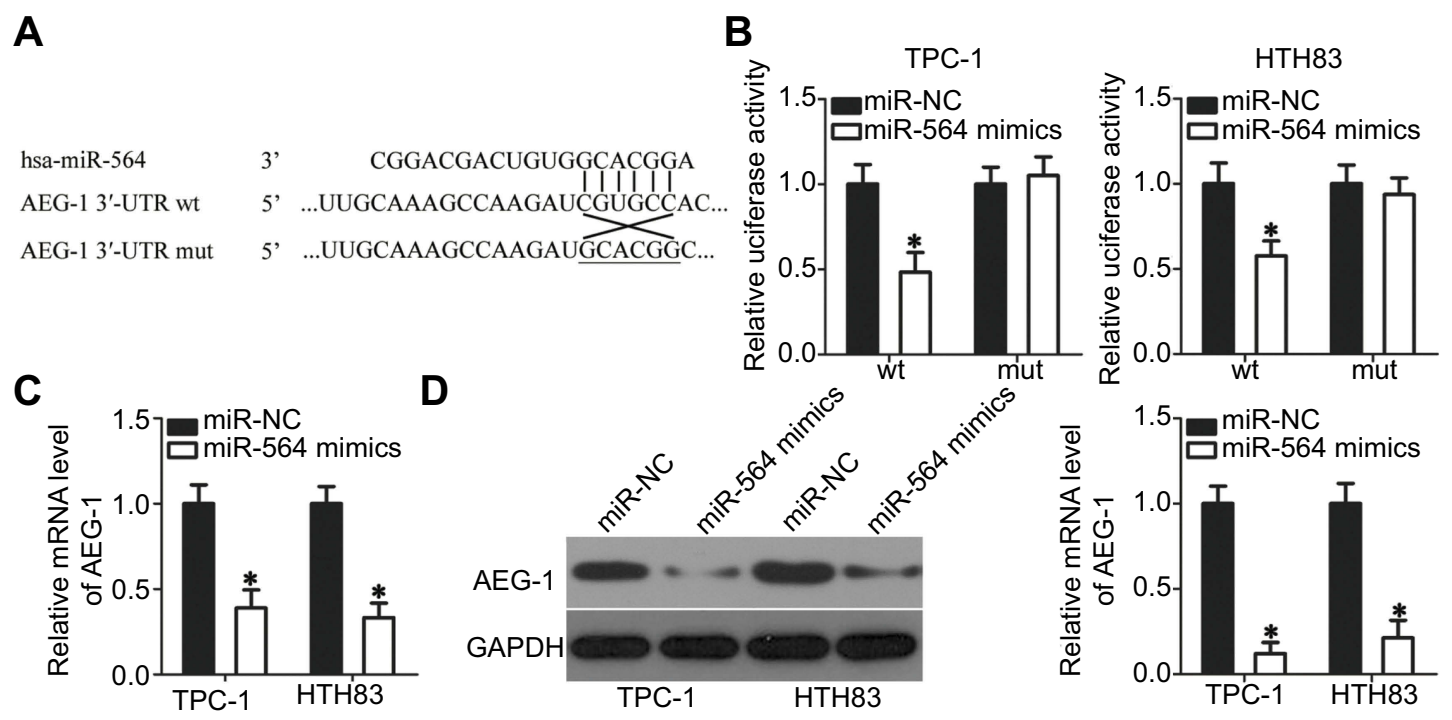

Figure 3 AEG-I is the direct target gene of miR-564 in PTC cells. (A) The miR-564 targeting sequences in the AEG-I 3'-UTR and mutant AEG-I 3'-UTR are shown. (B) Relative luciferase activity was measured in TPC-I and HTH83 cells after co-transfection with psiCHECK-wt-AEG-I-3'-UTR or psiCHECK-mut-AEG-I-3'-UTR and miR-564 mimics or miR-NC. ${ }^{*} P<0.05$ compared with miR-NC. (C and D) The AEG-I mRNA and protein levels were detected by RT-qPCR and Western blot analysis in TPC-I and HTH83 cells transfected with miR-564 mimics or miR-NC. $* P<0.05$ compared with miR-NC.

AEG-1 mRNA was significantly higher in PTC tissues than in normal adjacent tissues (Figure $4 \mathrm{~A}, P<0.05$ ). In addition, AEG-1 mRNA and protein levels were significantly higher in the low miR-564 expression group than in the high miR-564 expression group (Figure 4B and C, $P<0.05)$. Furthermore, Spearman's correlation analysis demonstrated that the expression levels of AEG-1 mRNA and miR-564 in PTC tissues were inversely correlated (Figure 4D; $\mathrm{R}^{2}=0.3727, P<0.0001$ ).

\section{Silenced AEG-I expression restrains the proliferation, migration, and invasion of PTC cells but promotes their apoptosis \\ in vitro}

To study the tumorigenic role of AEG-1 in PTC cells, AEG-1 expression was silenced in TPC-1 and HTH83 cells by transfection with AEG-1 siRNA. Western blot analysis, which was used to evaluate transfection efficiency, performed $72 \mathrm{hrs}$ following transfection demonstrated that AEG-1 protein expression had significantly reduced in TPC-1 and HTH83 cells transfected with AEG-1 siRNA (Figure 5A, $P<0.05$ ). AEG-1 knockdown particularly decreased cell proliferation (Figure $5 \mathrm{~B}, P<0.05$ ) and dramatically increased apoptosis (Figure $5 \mathrm{C}, P<0.05$ ) of TPC- 1 and HTH83 cells, as evidenced by MTT and cell apoptosis assays. Furthermore, transwell assay indicated that the migration (Figure 5D, $P<0.05$ ) and invasion (Figure 5E, $P<0.05$ )
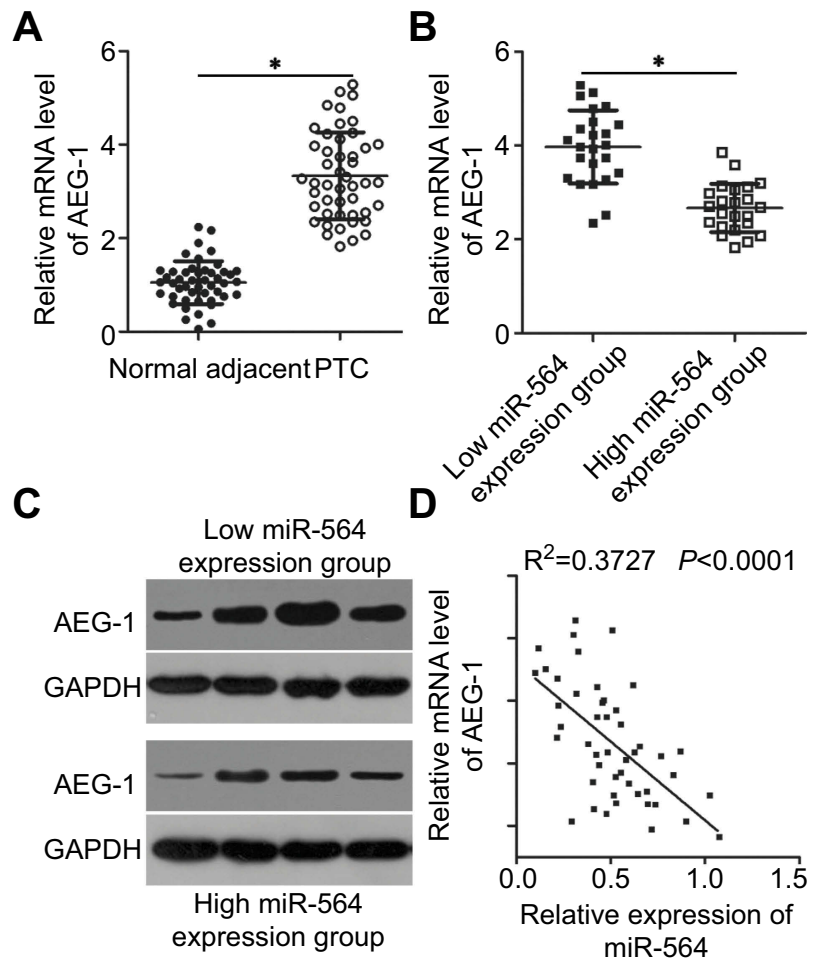

Figure 4 An inverse correlation between miR-564 and AEG-I mRNA levels was found in PTC tissues. (A) AEG-I mRNA expression was evaluated by RT-qPCR in 47 pairs of PTC and normal adjacent tissues. ${ }^{*} P<0.05$ compared with normal adjacent tissues. (B and C) Expression levels of AEG-I mRNA and protein in the high miR-564 expression group were significantly lower than those in the low miR-564 expression group. $P<0.05$ compared with the low miR-564 expression group. (D) Spearman's correlation analysis was applied to investigate the correlation between the expressions of miR-564 and AEG-I mRNA in PTC tissues. $R^{2}=0.3727, P<0.0001$.

of AEG-1-silenced TPC-1 and HTH83 cells has been significantly suppressed. Taken together, these results revealed 
A

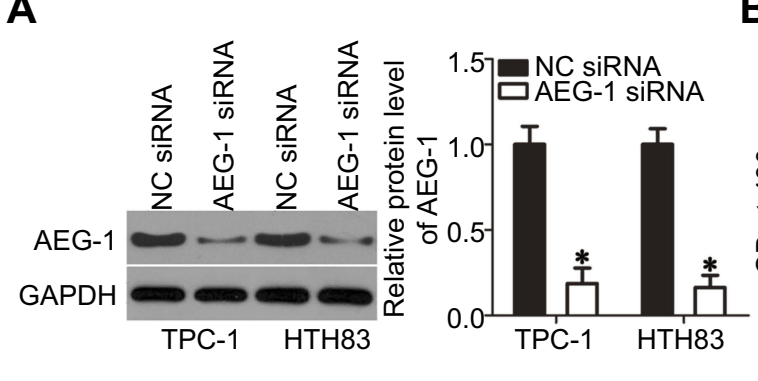

B

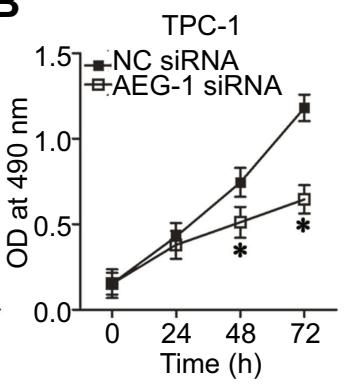

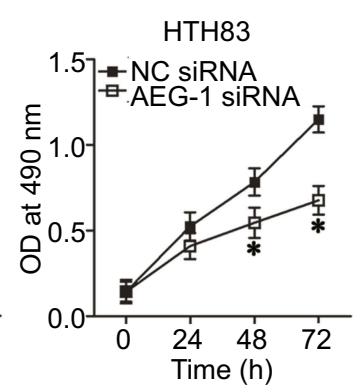

C
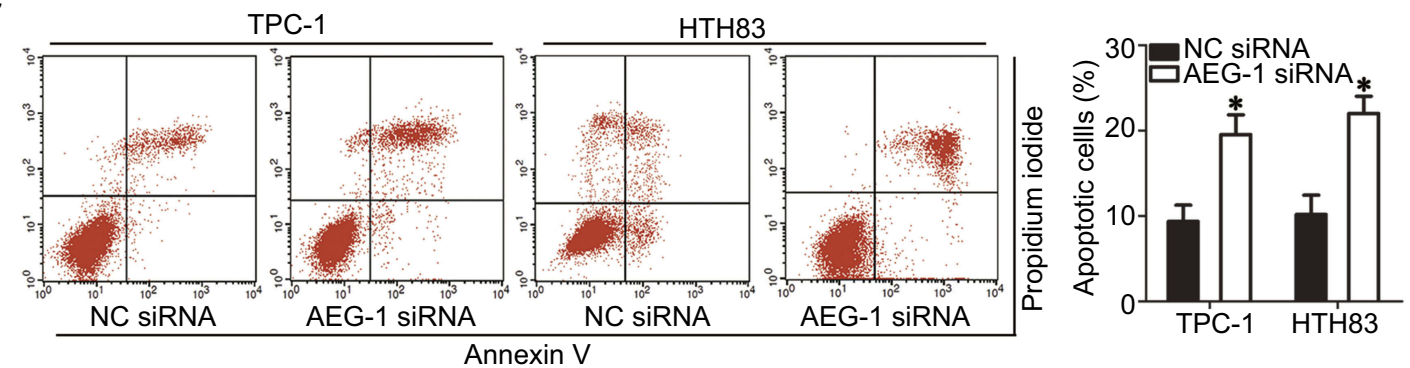

D
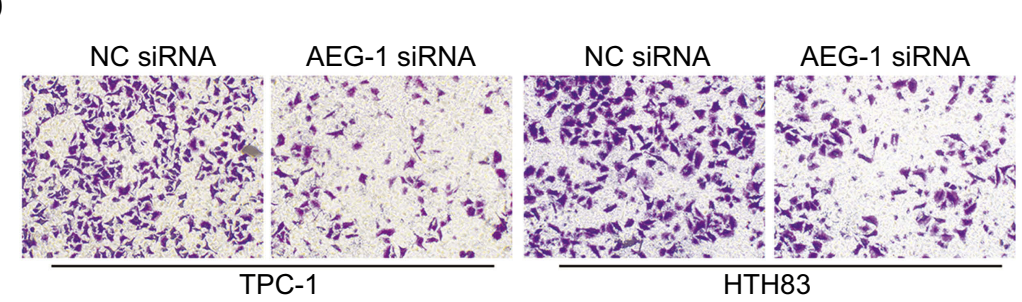

$\mathbf{E}$
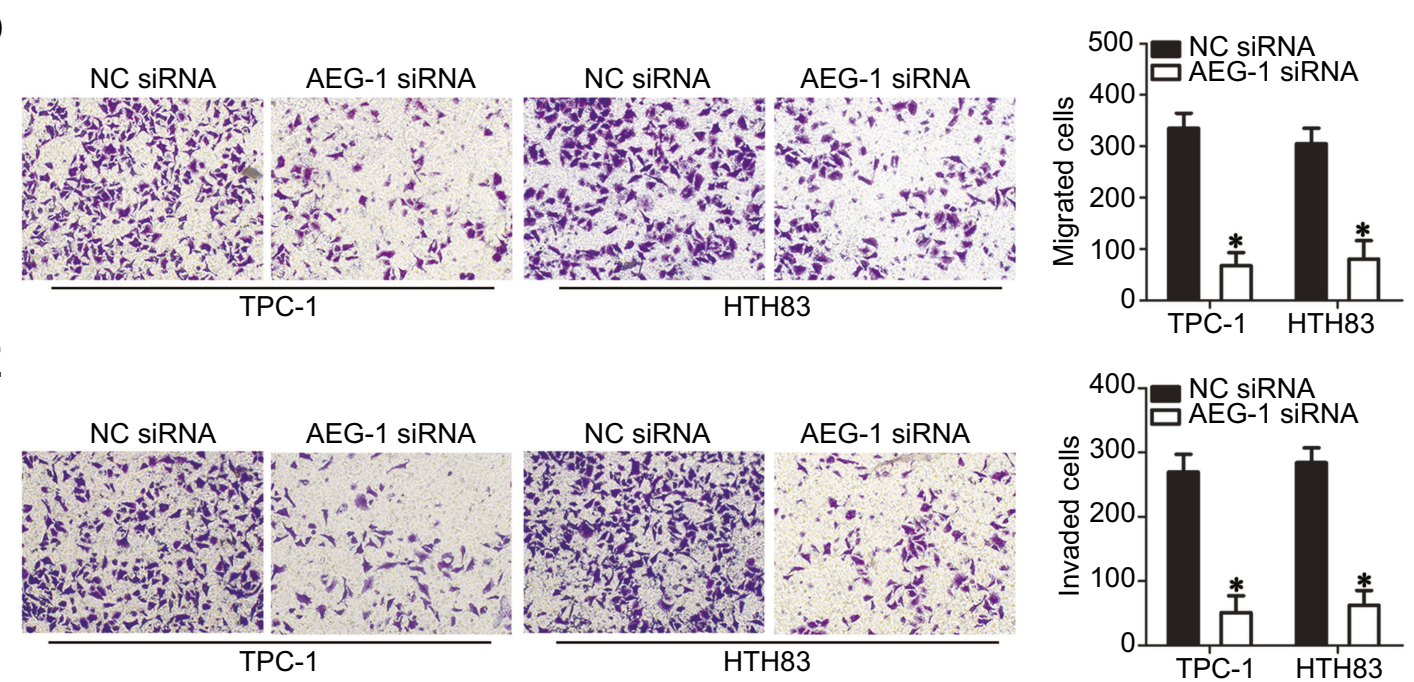

Figure 5 Silencing AEG-I expression simulates the action of miR-564 upregulation in PTC cells. TPC-I and HTH83 cells were transfected with AEG-I siRNA or NC siRNA. Transfected cells were used in the following assays. (A) AEG-I protein expression was detected by Western blot analysis in the aforementioned cells. $* P<0.05$ compared with NC siRNA. (B-E) The proliferation, apoptosis, migration, and invasion of AEG-I-silenced TPC-I and HTH83 cells were examined using MTT, cell apoptosis, and transwell assays, respectively. ${ }^{*} P<0.05$ compared with NC siRNA.

that AEG-1 downregulation exhibited a similar role as miR564 upregulation in PTC cells, further suggesting that AEG-1 is a direct downstream target of miR-564 in PTC.

\section{Reintroduction of AEG-I expression partially rescues the tumor-suppressive effects of miR-564 in PTC cells}

To further explore the functional relevance of miR-564 and AEG-1 in PTC, we used a series of rescue experiments to examine whether AEG-1 restoration could abolish miR-564-mediated effects in PTC cells. TPC-1 and
HTH83 cells with high miR-564 expression were transfected with the AEG-1 overexpression plasmid pc-AEG-1 or empty pcDNA3.1 plasmid. Western blot analysis was performed to detect AEG-1 expression in the rescue experiment. The protein level of AEG-1 was found to be downregulated in miR-564-overexpressing TPC-1 and HTH83 cells, whereas decreased AEG-1 protein expression could be restored in miR-564 mimic-transfected TPC1 and HTH83 cells after cotransfection with pc-AEG-1 (Figure 6A, $P<0.05$ ). Similarly, restoration of AEG-1 expression rescued the tumor-suppressing effects of miR564 upregulation on proliferation (Figure 6B, $P<0.05$ ), 
A

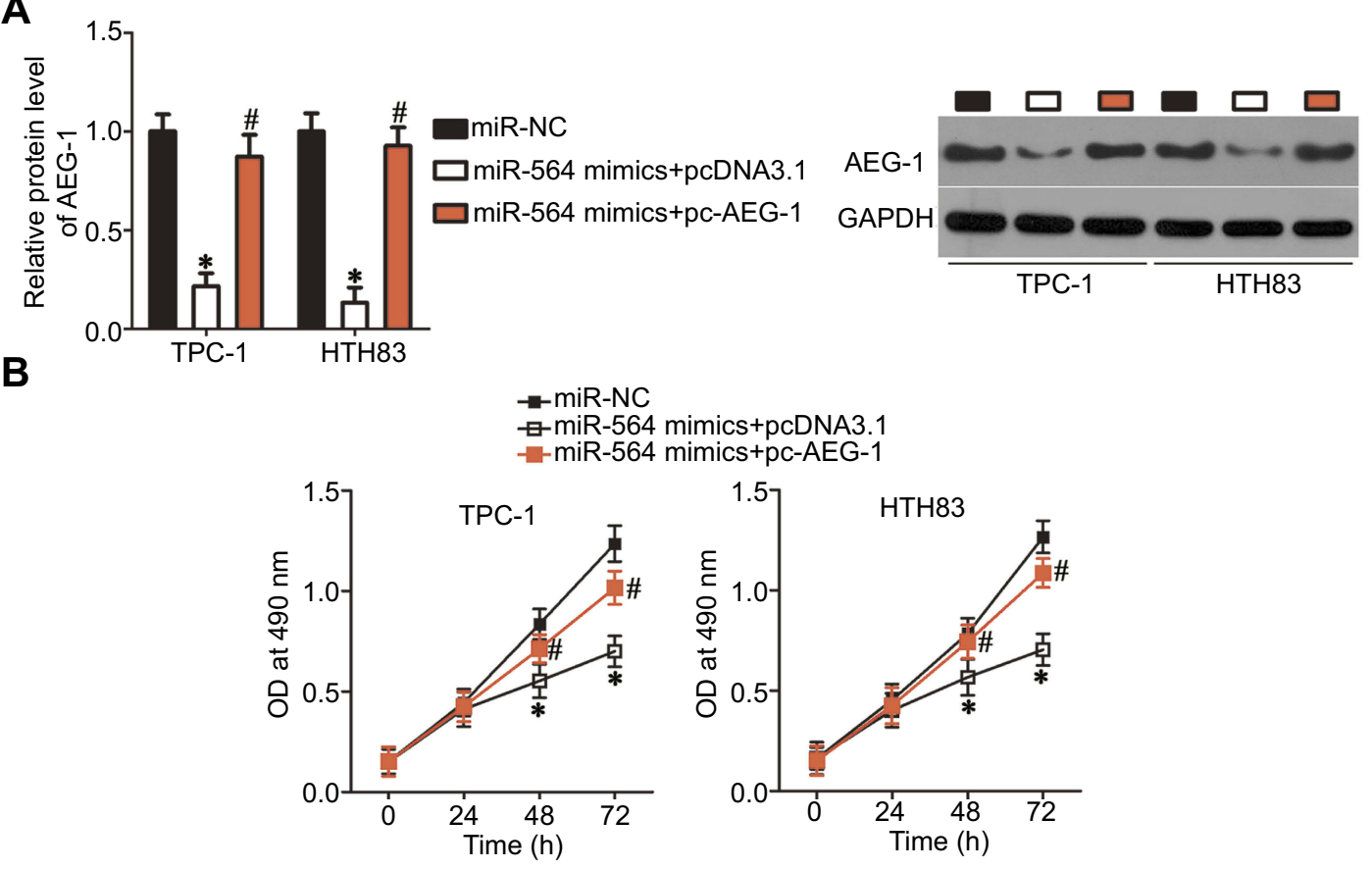

C
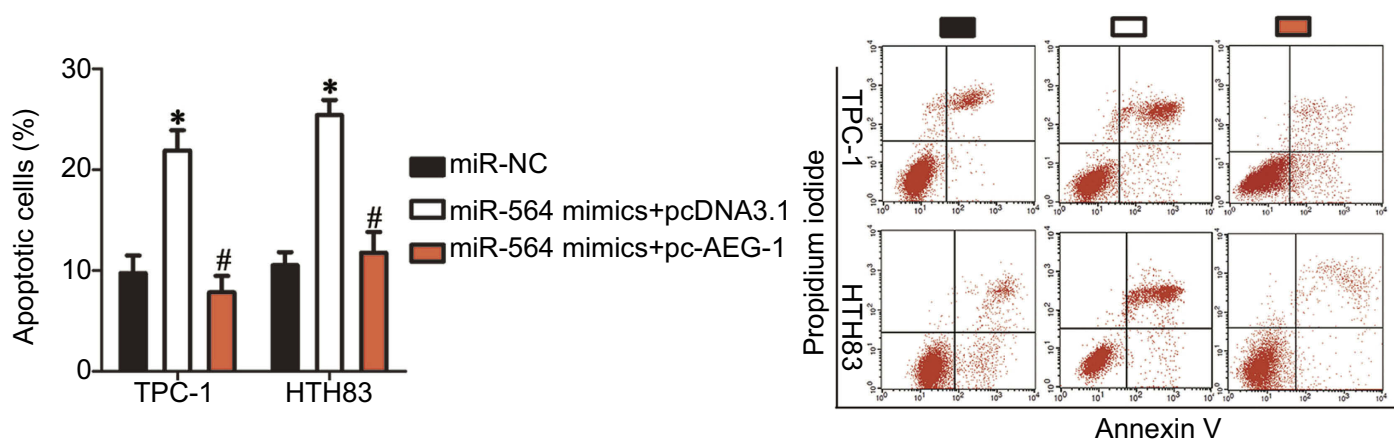

D
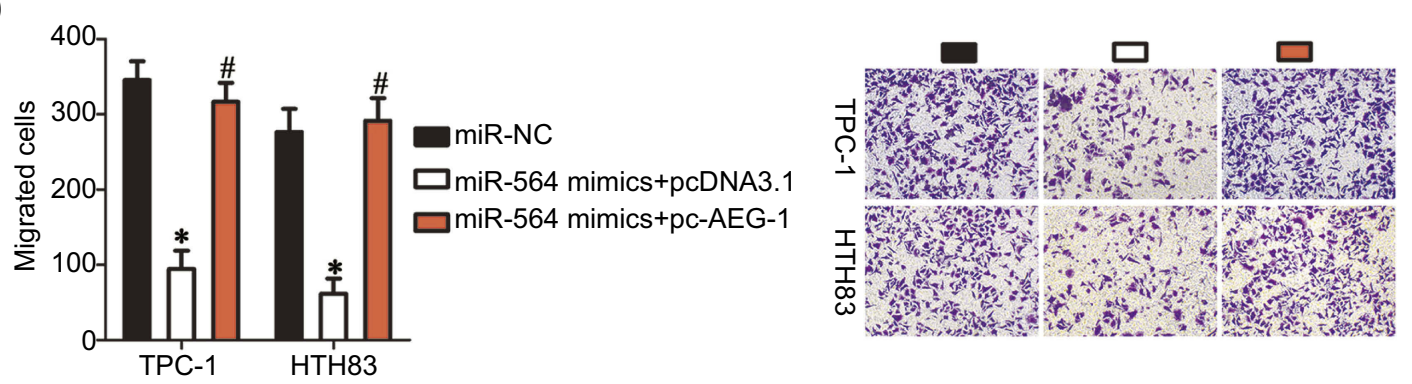

$\mathbf{E}$
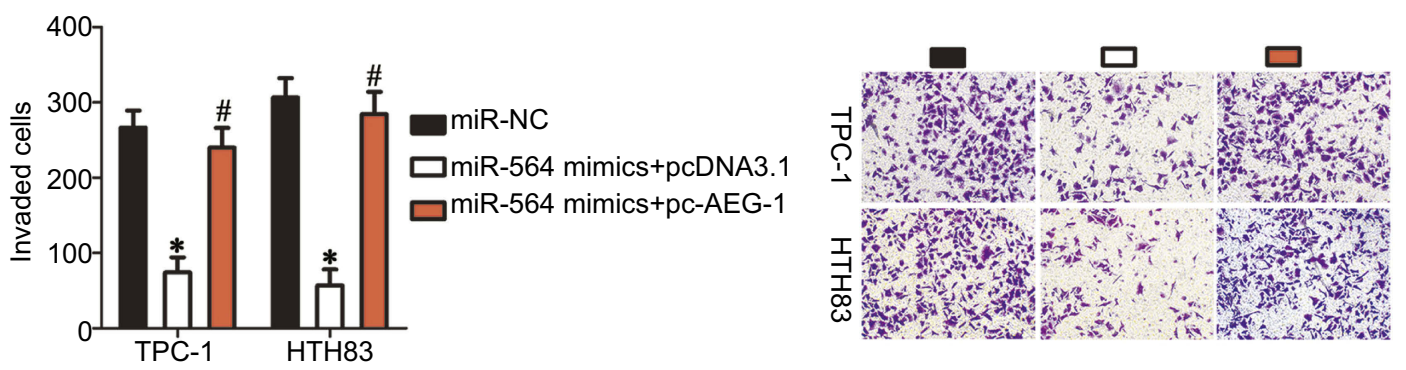

Figure 6 AEG-I restoration partially reverses the tumor-suppressive effects of miR-564 overexpression in PTC cells. (A) TPC-I and HTH83 cells were transfected with miR-564 mimics with pc-AEG-I or pcDNA3.I. Following transfection, AEG-I expression was measured by Western blot analysis. ${ }^{*} P<0.05$ compared with miR-NC; ${ }^{\#} P<0.05$ compared with miR-564 mimics+pcDNA3.I. (B and C) MTT and cell apoptosis assays were employed to evaluate cell proliferation and apoptosis of the aforementioned cells. ${ }^{*} P<0.05$ compared with miR-NC; ${ }^{*} P<0.05$ compared with miR-564 mimics+pcDNA3.I. (D and E) The migration and invasion in TPC-I and HTH83 cells treated as described above was investigated using transwell assays. ${ }^{*} P<0.05$ compared with miR-NC; ${ }^{*} P<0.05$ compared with miR-564 mimics $+p c D N A 3 . I$. 
apoptosis (Figure 6C, $P<0.05$ ), migration (Figure 6D, $P<0.05$ ), and invasion (Figure $6 \mathrm{E}, P<0.05$ ) of TPC-1 and HTH83 cells. These results suggest that AEG-1 is the real direct target of miR-564 and that it mediates, at least partially, the tumor-suppressive roles of miR-564 in the malignant development of PTC.

\section{miR-564 inactivates the PTEN/Akt signaling pathway in PTC cells}

Several studies have reported that AEG-1 is implicated in the PTEN/Akt pathway. ${ }^{30-32}$ Hence, we next attempted to examine whether miR-564 could inhibit the activation of the PTEN/Akt pathway in PTC cells. The protein levels of PTEN, p-Akt, and Akt were determined in TPC-1 and HTH83 cells following cotransfection with miR-564 mimics and pc-AEG-1 or pcDNA3.1. The protein level of PTEN was found to be significantly upregulated in TPC-1 and HTH83 cells upon miR-564 overexpression, whereas that of p-Akt was downregulated in miR-564overexpressing TPC-1 and HTH83 cells (Figure 7). The changes in PTEN and p-Akt expressions induced by miR564 upregulation were recovered in TPC-1 and HTH83 cells following cotransfection with pc-AEG-1 (Figure 7). These results suggest that miR-564 targets AEG-1 to deactivate the PTEN/Akt signaling pathway in PTC cells.

\section{miR-564 hinders the tumor growth of PTC cells in vivo by regulating the AEG-I/ PTEN/Akt pathway}

To examine the precise role of miR-564 in the growth of PTC cells in vivo, a tumor xenograft model was established by subcutaneously inoculating miR-564 mimics or miR-NC-transfected TPC-1 cells into nude mice. Tumor

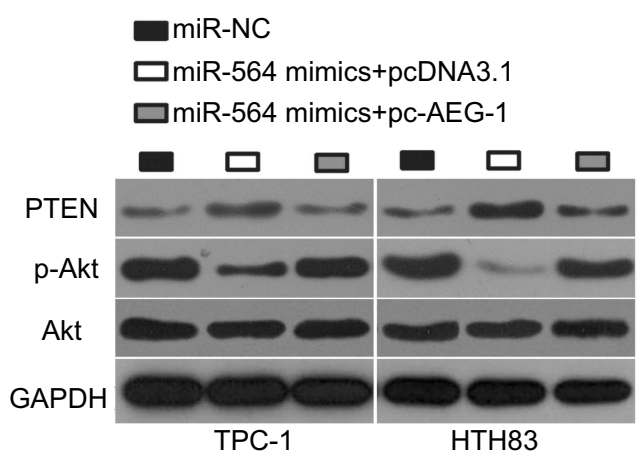

Figure 7 miR-564 attenuates the activation of the PTEN/Akt pathway in PTC cells. miR-564 mimics were co-transfected with pc-AEG-I or pcDNA3.I into TPC-I and HTH83 cells. Western blot analysis was conducted at $72 \mathrm{hrs}$ following transfection to detect the protein levels of PTEN, p-Akt, and Akt. xenografts in the miR-564 mimics group exhibited significant obvious tumor growth suppression compared with those in the miR-NC group (Figure $8 \mathrm{~A}$ and $\mathrm{B}, P<0.05$ ). Additionally, the tumor weight in the miR-564 mimics group significantly decreased compared with that in the miR-NC group (Figure $8 \mathrm{C}, P<0.05$ ). The data from RTqPCR proved that miR-564 expression were still upregulated in the excised tumor xenografts derived from the miR-564 mimics-transfected TPC-1 cells (Figure 8D, $P<0.05)$. Western blot analysis showed that the expression of AEG-1 and p-Akt was downregulated and that of PTEN was upregulated in the miR-564 mimics group compared with that in the miR-NC group (Figure 8E). These results suggest that miR-564 overexpression restrained the tumor growth of PTC cells in vivo by regulating the AEG-1/ PTEN/Akt pathway.

\section{Discussion}

In the past few years, several studies have focused on the expression profiles and biological roles of miRNA in PTC. ${ }^{17,33,34}$ An increasing number of miRNAs have been found to be dysregulated in PTC, and their dysregulation is believed to have important impacts on the formation and progression of PTC via a negative regulation of their target genes implicated in cellular biological behaviors. ${ }^{19,35,36}$ Hence, further investigation of the detailed roles of specific miRNAs in PTC might facilitate the identification of more effective targets for the treatment of patients with PTC. In the present study, to the best of our knowledge, we detected miR564 expression levels in PTC tissues and cell lines for the first time. Next, we explored the biological roles of miR-564 upregulation in PTC progression and clarified its associated molecular mechanisms and downstream signaling pathway. Our study revealed a significant role of the miR-564/AEG-1/ PTEN/Akt pathway in suppressing the development of PTC cells in vitro and in vivo.

miR-564 is downregulated in osteosarcoma tissues and cell lines. ${ }^{20,21}$ Decreased miR-564 expression is strongly linked to clinical stages and distant metastases in patients with osteosarcoma. Patients with osteosarcoma having low miR-564 expression exhibit shorter overall survival and disease-free survival than those with high miR-564 expression. Additionally, miR-564 is identified as an independent poor prognostic factor in patients with osteosarcoma. ${ }^{20}$ Decreased miR-564 expression is observed in hepatocellular carcinoma, and this decrease is substantially associated with tumor size, tumor number, and venous invasion. ${ }^{22}$ miR-564 downregulation has also been observed in prostate 
A

\section{C}

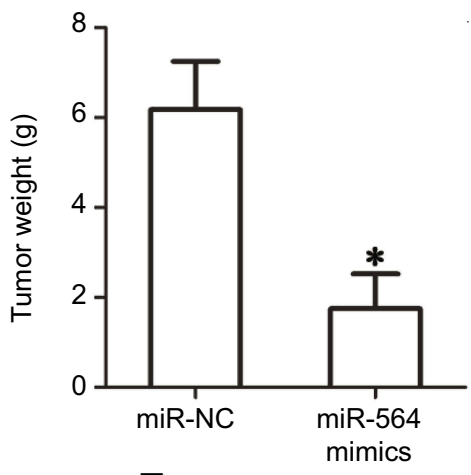

B

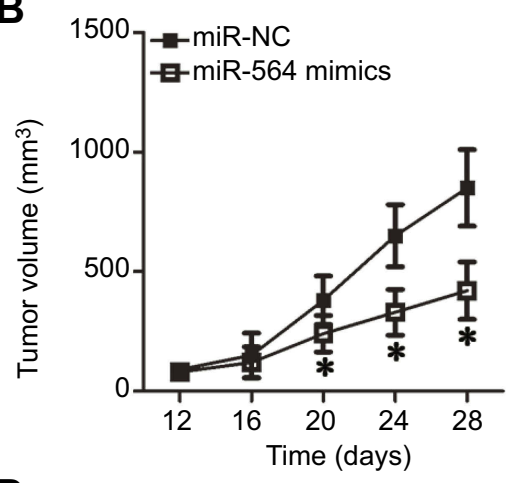

D

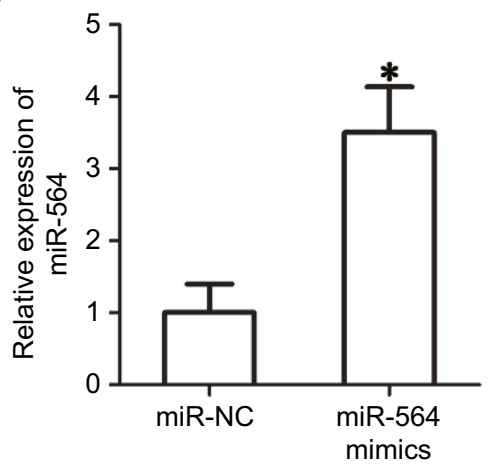

E

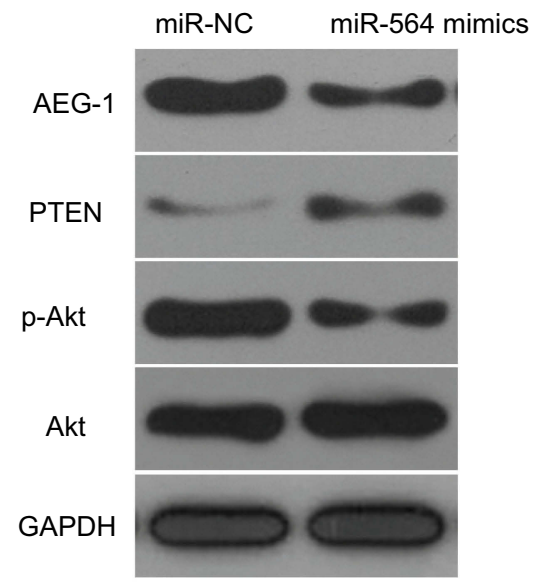

Figure 8 miR-564 overexpression inhibits tumor growth in vivo via the regulation of AEG-I/PTEN/Akt pathway. (A) Images of tumor xenografts derived from miR-564 mimics or miR-NC-transfected TPC-I cells. (B) The volume of tumor xenografts was monitored every 4 days and growth curves were generated. $* P<0.05$ compared with miR-NC. (C) The weight of tumor xenografts was measured after nude mice were sacrificed 4 weeks following inoculation. $* P<0.05$ compared with miR-NC. (D) Relative miR-564 expression in tumor xenografts was determined via RT-qPCR. $* P<0.05$ compared with miR-NC. (E) The protein levels of AEG-I, PTEN, P-Akt, and Akt in the excised tumor tissues were detected using Western blot analysis.

cancer, ${ }^{23}$ gastric cancer, ${ }^{24}$ glioblastoma, ${ }^{25}$ breast cancer, ${ }^{37}$ lung cancer, ${ }^{38}$ and chronic myeloid leukemia. ${ }^{39}$ However, the current knowledge about the expression profile of miR564 in PTC is limited. RT-qPCR analysis indicated that miR-564 expressed at low levels in PTC tissues and cell lines. miR-564 downregulation substantially correlated with lymph node metastasis and TNM stage in patients with PTC. These findings suggest that miR-564 is a potential prognosis predictor in patients with PTC.
miR-564 has been demonstrated to be a tumorsuppressive miRNA in many types of human malignancy. For instance, ectopic miR-564 expression attenuates proliferation and promotes apoptosis in osteosarcoma cells. ${ }^{21}$ Resumption of miR-564 expression inhibits hepatocellular carcinoma cell proliferation, migration, and invasion in vitro and decreases tumor growth in vivo. ${ }^{22}$ Upregulation of miR-564 suppresses cell growth and metastasis and induces cell cycle arrest in prostate 
cancer. $^{23}$ miR-564 restoration restricts the proliferative and invasive capacities of glioblastoma cells in vitro. ${ }^{25}$ Moreover, miR-564 exerts a tumor-suppressing role in the progression of breast $^{37}$ and lung ${ }^{38}$ cancers. Nevertheless, the functional role of miR-564 in the development of PTC remains unclear at present. In this study, a series of experiments demonstrated that miR-564 could inhibit cell proliferation, migration, and invasion of PTC cells in vitro; induce cell apoptosis in vitro; and hinder tumor growth in vivo. These findings suggest that miR564 is a promising target in the treatment of patients with PTC.

Several genes, including $\mathrm{Akt}^{21}$ in osteosarcoma, GRB2 in hepatocellular carcinoma, ${ }^{22}$ MLLT3in prostate cancer, $^{23}$ E2F3 in gastric cancer, ${ }^{24}$ and TGF- $\beta 1$ in glioblastoma, ${ }^{25}$ have been identified as direct targets of miR-564. To investigate this, we attempted to clarify the direct target gene involved in the antitumor role of miR564 in PTC cells. AEG-1, also known as metadherin, was found to be a novel direct downstream target of miR-564 in PTC cells. It is located on chromosome $8 \mathrm{q} 22$ and was first discovered in human fetal astrocytes in 2002. ${ }^{40}$ AEG-1 is highly expressed in PTC, and high AEG-1 expression is related to tumor size, lymph node metastasis, and distant metastasis. ${ }^{27}$ In addition, high expression levels of AEG-1 are closely correlated with recurrence-free survival in PTC patients. ${ }^{27}$ Cox regression analysis identifies AEG-1 expression as an independent prognostic indicator for recurrence-free survival in patients with PTC. $^{27}$ Functionally, AEG-1 has been acknowledged as an important regulator of PTC genesis and development by affecting a number of aggressive behaviors. $^{28,29}$ The current study demonstrated that miR564 upregulation inhibited the oncogenicity of PTC cells in vitro and in vivo by directly targeting AEG-1. Hence, miR-564 restoration-mediated silencing of AEG-1 expression might represent an attractive therapeutic strategy for patients with PTC.

\section{Conclusion}

This study is the first to provide evidence that miR-564 expression is downregulated in PTC and that this downregulation exhibits a significant association with lymph node metastasis and TNM stage in patients with PTC. Further, miR-564 exerts its tumor-suppressing roles in PTC, at least partially, by directly targeting AEG-1 and deactivating the PTEN/Akt pathway. This newly identified
miR-564/AEG-1PTEN/Akt pathway offers novel insights into the molecular mechanisms underlying PTC pathogenesis and suggests that this signaling pathway might be developed as a promising target for the management of patients with this malignant tumor.

However, there are two limitations to the current study. The correlation between miR-564 and the prognosis of PTC patients was not analyzed. In addition, the effect of miR-564 upregulation on in vivo tumor metastasis was not examined. These two limitations will be resolved in future experiments.

\section{Disclosure}

The authors report no conflicts of interest in this work.

\section{References}

1. Liebner DA, Shah MH. Thyroid cancer: pathogenesis and targeted therapy. Ther Adv Endocrinol Metab. 2011;2:173-195. doi:10.1177/ 2042018811419889

2. Ferlay J, Soerjomataram I, Dikshit R, et al. Cancer incidence and mortality worldwide: sources, methods and major patterns in GLOBOCAN 2012. Int $J$ Cancer. 2015;136:E359-E386. doi:10.1002/ijc. 29210

3. Carneiro RM, Carneiro BA, Agulnik M, Kopp PA, Giles FJ. Targeted therapies in advanced differentiated thyroid cancer. Cancer Treat Rev. 2015;41:690-698. doi:10.1016/j.ctrv.2015.06.002

4. N. Cancer Genome Atlas Research. Integrated genomic characterization of papillary thyroid carcinoma. Cell. 2014;159:676-690. doi:10.1016/j.cell.2014.09.050

5. Nikiforov YE. Thyroid carcinoma: molecular pathways and therapeutic targets. Modern Pathol. 2008;21(Suppl 2):S37-S43. doi:10.1038/ modpathol.2008.10

6. Xing M. Molecular pathogenesis and mechanisms of thyroid cancer. Nature reviews. Cancer. 2013;13:184-199. doi:10.1038/nrc3431

7. Frohlich E, Wahl R. The current role of targeted therapies to induce radioiodine uptake in thyroid cancer. Cancer Treat Rev. 2014;40:665-674. doi:10.1016/j.ctrv.2014.01.002

8. Shi X, Liu R, Basolo F, et al. Differential clinicopathological risk and prognosis of major papillary thyroid cancer variants. J Clin Endocrinol Metab. 2016;101:264-274. doi:10.1210/jc.2015-2917

9. Esquela-Kerscher A, Slack FJ. Oncomirs - microRNAs with a role in cancer.Nature reviews. Cancer. 2006;6:259-269. doi:10.1038/ $\operatorname{nrc} 1840$

10. Griffiths-Jones S. miRBase: microRNA sequences and annotation. Current Protoc Bioinformatics. 2010;29(1):12.9.1-12.9.10.

11. Guo H, Ingolia NT, Weissman JS, Bartel DP. Mammalian microRNAs predominantly act to decrease target mRNA levels. Nature. 2010;466:835-840. doi:10.1038/nature09267

12. Saliminejad K, Khorram Khorshid HR, Soleymani Fard S, Ghaffari SH. An overview of microRNAs: biology, functions, therapeutics, and analysis methods. J Cell Physiol. 2019;234(5):54515465.

13. Delsin LEA, Salomao KB, Pezuk JA, Brassesco MS. Expression profiles and prognostic value of miRNAs in retinoblastoma. J Cancer Res Clin Oncol. 2019;145(1):1-10.

14. Szymczyk A, Macheta A, Podhorecka M. Abnormal microRNA expression in the course of hematological malignancies. Cancer Manag Res. 2018;10:4267-4277. doi:10.2147/CMAR.S174476 
15. Yi T, Zhou X, Sang K, Zhou J, Ge L. MicroRNA-1270 modulates papillary thyroid cancer cell development by regulating SCAI. Biomed Pharmacother. 2019;109:2357-2364. doi:10.1016/j. biopha.2018.08.150

16. Jia M, Shi Y, Li Z, Lu X, Wang J. MicroRNA-146b-5p as an oncomiR promotes papillary thyroid carcinoma development by targeting CCDC6. Cancer Lett. 2018;443:145-156. doi:10.1016/j. canlet.2018.11.026

17. Yu C, Zhang L, Luo D, et al. MicroRNA-146b-3p promotes cell metastasis by directly targeting NF2 in human papillary thyroid cancer. Thyroid. 2018. doi:10.1089/thy.2017.0626

18. Pishkari S, Paryan M, Hashemi M, Baldini E, Mohammadi-Yeganeh $\mathrm{S}$. The role of microRNAs in different types of thyroid carcinoma: a comprehensive analysis to find new miRNA supplementary therapies. J Endocrinol Invest. 2018;41:269-283. doi:10.1007/ s40618-017-0735-6

19. Perdas E, Stawski R, Nowak D, Zubrzycka M. The role of miRNA in papillary thyroid cancer in the context of miRNA let-7 family. Int J Mol Sci. 2016;17. doi:10.3390/ijms17060909

20. Gao F, Xu F. Reduced expression of miR-564 is associated with worse prognosis in patients with osteosarcoma. Eur Rev Med Pharmacol Sci. 2018;22:5851-5856. doi:10.26355/eurrev_201 80915912

21. Ru N, Zhang F, Liang J, et al. MiR-564 is down-regulated in osteosarcoma and inhibits the proliferation of osteosarcoma cells via targeting Akt. Gene. 2018;645:163-169. doi:10.1016/j.gene.2017. 12.028

22. Liang $\mathrm{C}, \mathrm{Xu} \mathrm{Y}, \mathrm{Ge} \mathrm{H}$, et al. miR-564 inhibits hepatocellular carcinoma cell proliferation and invasion by targeting the GRB2-ERK1/ 2-AKT axis. Oncotarget. 2017;8:107543-107557. doi:10.18632/ oncotarget.22504

23. Meng FJ, Meng FM, Wu HX, Cao XF. miR-564 inhibited metastasis and proliferation of prostate cancer by targeting MLLT3. Eur Rev Med Pharmacol Sci. 2017;21:4828-4834.

24. Guo Y, Qi Y, Guo A, Du C, Zhang R, Chu X. miR-564 is downregulated in gastric carcinoma and targets E2F3. Oncol Lett. 2017;13:4155-4160. doi:10.3892/ol.2017.5964

25. Jiang C, Shen F, Du J, et al. MicroRNA-564 is downregulated in glioblastoma and inhibited proliferation and invasion of glioblastoma cells by targeting TGF-beta1. Oncotarget. 2016;7:56200-56208. doi:10.18632/oncotarget.8987

26. Livak KJ, Schmittgen TD. Analysis of relative gene expression data using real-time quantitative PCR and the 2(-Delta Delta C(T)) method. Methods. 2001;25:402-408. doi:10.1006/ meth.2001.1262

27. Li WF, Wang G, Zhao ZB, Liu CA. High expression of metadherin correlates with malignant pathological features and poor prognostic significance in papillary thyroid carcinoma. Clin Endocrinol (Oxf). 2015;83:572-580. doi:10.1111/cen. 12683
28. Huang LL, Wang Z, Cao CJ, et al. AEG-1 associates with metastasis in papillary thyroid cancer through upregulation of MMP2/9. Int J Oncol. 2017;51:812-822. doi:10.3892/ijo.2017.4074

29. Jiang W, Wang S, Sun Y, Jiang Y, Yu T, Wang J. Overexpression of microRNA-448 inhibits osteosarcoma cell proliferation and invasion through targeting of astrocyte elevated gene-1. Mol Med Rep. 2017;16:5713-5721. doi:10.3892/mmr.2017.7249

30. Li WF, Ou Q, Dai H, Liu CA. Lentiviral-mediated short hairpin RNA knockdown of MTDH inhibits cell growth and induces apoptosis by regulating the PTEN/AKT pathway in hepatocellular carcinoma. Int J Mol Sci. 2015;16:19419-19432. doi:10.3390/ijms160819419

31. Li WF, Dai H, Ou Q, Zuo GQ, Liu CA. Overexpression of microRNA-30a-5p inhibits liver cancer cell proliferation and induces apoptosis by targeting MTDH/PTEN/AKT pathway. Tumour Biol. 2016;37:5885-5895. doi:10.1007/s13277-015-4456-1

32. Li L, Zhang H. MicroRNA-379 inhibits cell proliferation and invasion in glioma via targeting metadherin and regulating PTEN/AKT pathway. Mol Med Rep. 2018;17:4049-4056. doi:10.3892/ mmr.2017.8361

33. Gao XB, Chen CL, Tian ZL, Yuan FK, Jia GL. MicroRNA-791 is an independent prognostic factor of papillary thyroid carcinoma and inhibits the proliferation of PTC cells. Eur Rev Med Pharmacol Sci. 2018;22:5562-5568. doi:10.26355/eurrev 201809 15819

34. Yan R, Yang T, Zhai H, Zhou Z, Gao L, Li Y. MicroRNA-150-5p affects cell proliferation, apoptosis, and EMT by regulation of the BRAF(V600E) mutation in papillary thyroid cancer cells. $J$ Cell Biochem. 2018;119:8763-8772. doi:10.1002/jcb.27108

35. Zembska A, Jawiarczyk-Przybylowska A, Wojtczak B, Bolanowski M. MicroRNA expression in the progression and aggressiveness of papillary thyroid carcinoma. Anticancer Res. 2019;39:33-40. doi:10.21873/anticanres.13077

36. Zhu G, Xie L, Miller D. Expression of MicroRNAs in thyroid carcinoma. Methods Mol Biol. 2017;1617:261-280. doi:10.1007/ 978-1-4939-7046-9_19

37. Mutlu M, Saatci O, Ansari SA, et al. miR-564 acts as a dual inhibitor of PI3K and MAPK signaling networks and inhibits proliferation and invasion in breast cancer. Sci Rep. 2016;6:32541. doi:10.1038/ srep32541

38. Yang B, Jia L, Guo Q, et al. MiR-564 functions as a tumor suppressor in human lung cancer by targeting ZIC3. Biochem Biophys Res Commun. 2015;467:690-696. doi:10.1016/j.bbrc.2015.10.082

39. Rokah OH, Granot G, Ovcharenko A, et al. Downregulation of miR-31, miR-155, and miR-564 in chronic myeloid leukemia cells. PLoS One. 2012;7:e35501. doi:10.1371/journal.pone.0035501

40. Su ZZ, Kang DC, Chen Y, et al. Identification and cloning of human astrocyte genes displaying elevated expression after infection with HIV-1 or exposure to HIV-1 envelope glycoprotein by rapid subtraction hybridization, RaSH. Oncogene. 2002;21:3592-3602. doi:10.10 38/sj.onc. 1205445
OncoTargets and Therapy

\section{Publish your work in this journal}

OncoTargets and Therapy is an international, peer-reviewed, open access journal focusing on the pathological basis of all cancers, potential targets for therapy and treatment protocols employed to improve the management of cancer patients. The journal also focuses on the impact of management programs and new therapeutic agents and protocols on patient perspectives such as quality of life, adherence and satisfaction. The manuscript management system is completely online and includes a very quick and fair peer-review system, which is all easy to use. Visit http://www.dovepress.com/ testimonials.php to read real quotes from published authors. 